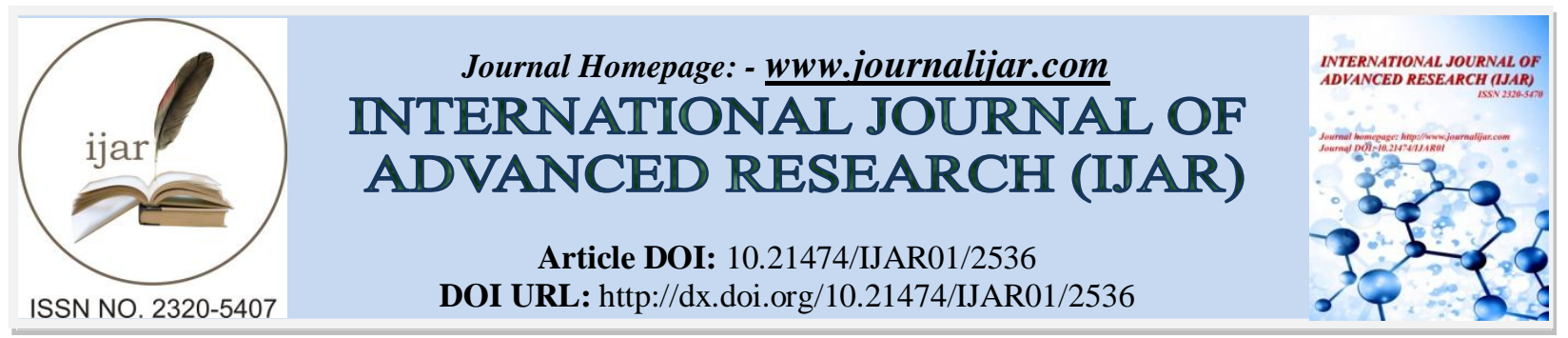

RESEARCH ARTICLE

\title{
STUDIES OF MORPHOLOGICAL AND SECONDARY METABOLITES VARIATY OF MOSSES (BRYOPHYTA) IN CIBODAS, WEST JAVA.
}

Susilo And Rizkia Suciati.

Departement of Biology Education, Muhammadiyah University of Prof. DR. HAMKA . Jl.Tanah Merdeka, Kampung Rambutan, Ciracas, Jakarta Timur 13830, Indonesia .

\section{Manuscript Info}

.........................

Manuscript History

Received: 25 October 2016

Final Accepted: 23 November 2016

Published: December 2016

Key words:-

Bryophyta;Indonesian; Secondary metabolites;TLC; UPGMA;

\section{Abstract}

Mosses is a species of exotic and charming with a unique combination of characteristics of each of its members. In Indonesia, this species can grow lush and abundant, however it was not a lot of investigate for content of this plant. This study aims to determine the diversity of bryophyta views by morphological and secondary metabolites. This research used descriptive method with qualitative approach. Sampling was conducted in four locations in Bogor Indonesian Regency by randomly. Analysis of the data used descriptive analysis to find the value of $\mathrm{Rf}$ (Retardation Factor) which converted into a form of the data with UPGMA (Unweighted Pair Group Method with Arithmetic Mean) model. The results showed that four types has been founded, namely Dicranella sp., Funaria hygrometrica Hedwig, Bryum billardierii Schwaegr and Pogonatum contortum Brid. Profile content of secondary metabolites showed that Dicranella sp., B. Billardierii, $F$. hygrometrica and $P$. contortum contained alkaloids, phenolics, triterpenoids/steroids and terpenoids. Kinship at the level of morphological traits and characteristics content of the secondary metabolites presented that Funaria hygrometrica Hedwig and Bryum billardierii Schwaegr (66.67\%) have a closer kinship than among Dicranella sp and Funaria hygrometrica Hedwig (63.64\%) meanwhile between Bryum billardierii Schwaegr and Pogonatum contortum Brid (51.52\%).

Copy Right, IJAR, 2016,. All rights reserved.

\section{Introduction:-}

Indonesia is an archipelago in tropical regions that have a high biodiversity. Plant species in Indonesia was estimated to have $60 \%$ of the flora from about 2 million flora around the world, and about 350,000 species of flowering plants, while a number of the 18,000 species are mosses, which $40 \%$ of the species are endemic or founded only in Indonesia. However, the information has not still exploited in depth, especially when associated with secondary metobolit compounds found in moss.

Mosses (Bryophyta) was a low-level plants that live on land and generally wet and humid place. Moss plants could live in soil, rocks, wood and even the walls of a building (Tjirosoepomo, 1986). The diversity of mosses plants can be seen from the morphological characteristics and content of secondary metabolites (Chemotaxonomic). Plant morphology studies the shape and composition of the plant's body (Hasan and Ariyanti, 2004). Plants have been

Corresponding Author:- Susilo And Rizkia Suciati.

Address:- Departement of Biology Education, UHAMKA Jl.Tanah Merdeka, Kampung Rambutan, Ciracas, Jakarta Timur, Indonesia 13830. 
evolving to adapt the environment with genetic encoding of useful and diverse synthases for secondary metabolites (Waterman, 1992).

The diversity of mosses by the content characteristic of secondary metabolites (Chemotaxonomic) could be used as an explanation or confirmation in the study of plant taxonomy, and at times can also be used as a correction tool in structuring a business classification system (Banthorpe, 1994; Muzayyinah, 2005). Buchanan, et al.,(2012), argued also that the presence or absence of typical secondary metabolites, structures of characteristics comparison and crossed biosynthesis of these compounds can be used as a taxonomy feature when other taxonomy (morphology) were difficult to use for removal of the state of the taxon between two tribes or two clans which were related. In addition, Chemotaxonomic also plays an important role in assessing the compounds which could be used as ingredients for pharmaceuticals (Glime, et al., 2007).

The qualitative research of chemical compounds against all kinds of mosses which grow in Indonesia has not been commonly done, especially when it is associated with taxonomic status and relationships, and also secondary metabolites from each species of mosses. Though Indonesia has a high diversity of moss. Based on these descriptions, it needs to be studied further on mosses species diversity by morphological characteristics and content of secondary metabolites. This research is expected to provide information about the opportunities to utilize and develop the potential of mosses plants in Indonesia and can be used as learning material development.

\section{Material And Methods:-}

This study was conducted in April 2015 until January 2016. Sampling was established from mosses colection in Cibodas National Park, Indonesia. This research was a qualitative descriptive study.

\section{Data Collection Techniques:-}

Intake of mosses has been done by exploring (survey) the relative area overgrown with mosses plants and then it is selected by purposive random. Chemistry profile with chloroform extracts was analyzed using thin layer chromatography (TLC). Each of chloroform extract was spotted on a TLC plate with a stationary phase of silica gel and eluted using a mobile phase such as chloroform-n-hexane (9:1 v/v) in the developer vessel. Chemical content profile of each extract was detected using a $\mathrm{UV}_{254} \mathrm{~nm}$ beam and sprayed with Cerium Sulfate reagent for detecting components of organic compounds. Parameters measured were chemical composition mosses and Retardation Factor (Rf) (Setiawan, 1996).

Types of composing compounds were identified based on the value of $\mathrm{Rf}$ formed on the chromatogram that can be formulated as follows (Gritter et al., 1991).

$$
\mathrm{Rf}=\frac{\text { Movement Distance of solutes }}{\text { Movement Distance of solvent }}
$$

Pinch or ribbon formed from the thin-layer chromatography were detected using special spray Ferri (III) Chloride (to determine the content of phenolic compounds), Dradgendorf (to determine the content of alkaloids), Vanilin Sulfate (to know terpenoids) and Lieberman Burchad (for knowing compound triterpenoids/steroids) reagent.

\section{Data Analysis Techniques:-}

Morphological characteristics and type of the composing compounds of secondary metabolites data of mosses are tabulated in binary ( 0 and 1 ) and made dendogram. Each morphological characteristics and the types of compounds that are visibleare named a value of 1, while morphological characteristics and types of compounds that does not visible is rated 0. If a compound was always apparent in all species, then it was determined based on the levels (Sneath and Sokal, 1973; Justin, et al., 2012).

Compounds whose levels were equal to or above the average is rated 1, while it is below average it is rated as 0 . Dendogram is made numerically by an association grouping method where the rate of equation of association coefficient was determined by the calculation model in UPGMA, which was computed in Numerical Taxonomy and Multivariate Analysis System version 2.2 (NTSYS) program. 


\section{Results:-}

Secondary metabolites, also known as phytochemicals, natural products or plant constituents are responsible for medicinal properties of plants to which they belong. Natural products are an important source of drug candidates in pharmaceutical industry, more deeply we understand them, the easier it is for scientists to intervene in alleviating different kind of diseases.

\section{Plant Morphology of Mosses:-}

In April and May 2015, sampling of mosses had been conducted. Sampling was done by random purposive, covering four zone in Cibodas National Park, West Java, Indonesia.

From the four areas of sampling has been found four species belonging to four families. Mosses was found on the wall of the hedgerow, logs, trees and stones. From the various types of mosses obtained, all belong to the leaf moss (musci). The types of mosses could be seen in Table 1below.

Table 1:- Types of mosses (Bryophyta) found

\begin{tabular}{|l|l|}
\hline \multicolumn{1}{|c|}{ Species } & \multicolumn{1}{c|}{ Families } \\
\hline Dicranella sp & Dicranaceae \\
\hline Funaria hygrometrica & Funnariaceae \\
\hline Bryum billardierii Schwaegr & Bryaceae \\
\hline Pogonatum contortum Brid & Polytrichaceae \\
\hline
\end{tabular}

Based on the morphological observation, it was found four types of mosses. The species could be seen in Figure 1 below.

Fig 1.(a) Dicranella sp, (b) Funaria hygrometrica, (c) Bryum billardierii (d) Pogonatum contortum
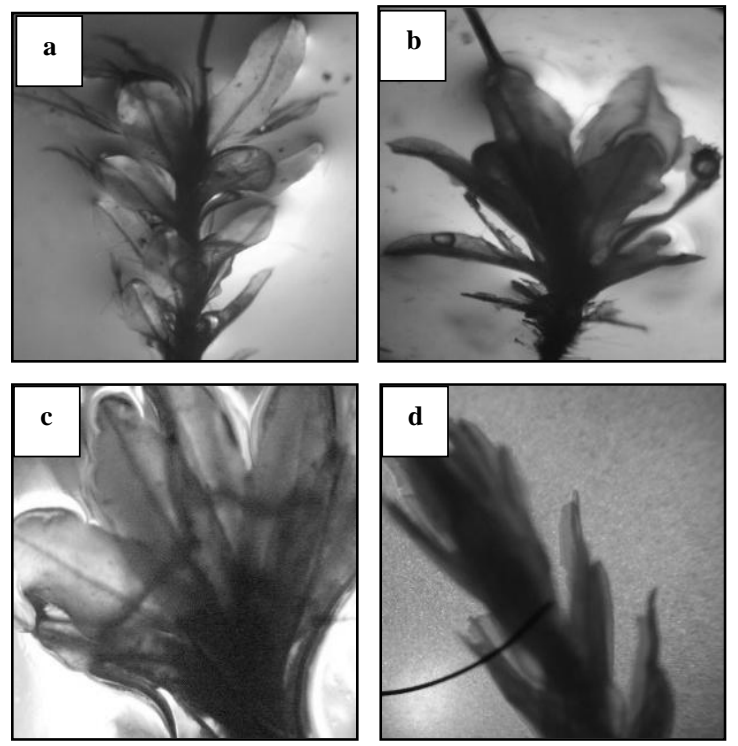

\section{Discussion:-}

\section{Analysis of Secondary Metabolites Compounds:-}

In this research, the analysis of the Chemotaxonomic in form of secondary metabolites that were performed using Thin Layer Chromatography with several reagents to obtain patches with color and different Retardation Factor (Rf) (Harborne, 1987). The distinct Color and Retardation Factor (Rf) showed the content of secondary metabolites in mosses. Based on the results obtained by maceration with chloroform dry weight of each sample Dicranella sp, $F$. hygrometrica, B.billardierri and $P$. contortum sequentially 18.6 grams, 53.4 grams, 43 grams and 13 grams. The percentage of the dry weight of chloroform extract to Dicranella sp, F. hygrometrica, $B$. billardierri and $P$. contortum were $37.03 ; 52.87 ; 59.14$ and 46.88 respectively, which means it was varied. This difference happened because the different of percentage content of secondary metabolites solubility of each sample in chloroform (Edward, 1991). 


\section{Profile Analysis of Chemical Ingredients:-}

Profile of chloroform extract compounds can be determined by using thin layer chromatography (TLC) with silica $\mathrm{GF}_{254}$ stationary phase and a mobile phase of chloroform-n-hexan $(9: 1 \mathrm{v} / \mathrm{v})$. Content profile of the compounds contained in each extract can be seen in Figure 2.

Fig 2. Chromatogram chloroform extract talus mosses with GF254 silica stationary phase and a mobile phase of chloroform: n-hexan (9: $1 \mathrm{v} / \mathrm{v}$ ). Detection is used (a) visible light, (b) UV254, and (c) common reagents cerium

(IV) Sulfate.1. Dicranella sp; 2. F.hygrometrica; 3. B. Billardierri; 4. P. contortum
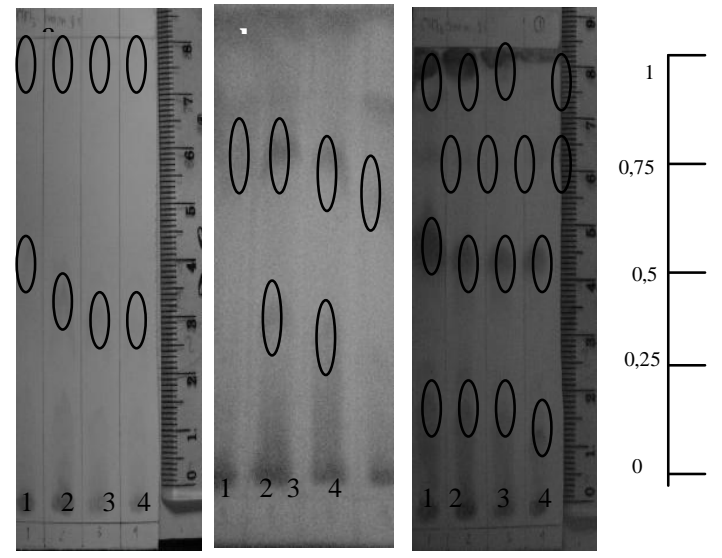

Color reaction on the reagent spray Cerium (IV) sulfate mechanism was that Cerium (IV) sulfate consisting of concentrated sulfuric acid and acetic anhididra, where concentrated sulfuric acid has a destructive and oxidative properties. More prominent destructive nature would undermine the compound so that spot becomes brown. The mechanism of color on the spray gragendorff reagent was a composition gragendorff composed of Bismuth Subnitrat, Acetic Acid Glacial and Potassium iodide binds to the amine (group N) reaction occurred, causing the orange color indicating the nitrogenous bases (Justin, et al., 2012; Liu et al., 1998).

\section{Analysis of Chemical Group:-}

Having in mind the profile of chemical compounds then TLC plate is sprayed using three special reagent, which is a special reagent Liebermann Burchard, a special reagent Dragendorf special reagent Ferri (III) Chloride and Sulfate vanilin special reagents.

Cerium (IV) sulfate was common reagent for detection of compounds. Detection of this spray can be used for any class of compounds. Detection is shown with brown spots. Liebermann Burchad is a special reagent for detecting of compounds triterpenoids/steroids. Positive detection spot is indicated by the green-blue or blue-green. Vanillin Sulfate is a special reagent for detection of compounds terpenoids. Positive detection was depicted with purple spots. Dragendorff is a special reagent for detection of alkaloid compounds. Positive detection was indicated by the orange colored spots. $\mathrm{FeC}_{13}$ was a special reagent for detection of phenolic compounds. Positive detection was shown with brown spots. Classes of compounds contained in extracts of chloroform was a class of triterpenoids / steroids, where in the chromatogram of chloroform extract with spray reagent Liebermann Burchad visible bluishgreen color.

Alkaloids in the chromatogram of chloroform extract with spray reagent Dragendorf present with orange color and phenolic on the chromatogram of chloroform extract with spray reagent Ferri (III) Chloride visible brown color (Kutchan, 2001). At detection by spraying Liebermann Burchad to detect triterpenoids or steroids, followed by using a spray reagent Vanilin Sulfate and spot colors generated significant positive for terpenoids. Profile content of secondary metabolites by the compound indicates that Dicranella sp contains alkaloids, phenolics, triterpenoids / steroids and terpenoids; $F$. hygrometricacontains alkaloids, phenolics, triterpenoids/steroids and terpenoids; $B$. billardierii contains alkaloids, phenolics, triterpenoids/steroids and terpenoids and $P$. contortum contains alkaloids, triterpenoids/steroids and terpenoids. 


\section{Analysis of Phylogenetic Moss Based onMorphology and Secondary Metabolites:-}

Comparison table of morphological characteristics and content of secondary metabolites can be seen in Table 1 . From these data, when analyzed using a similarity index dendogram obtained as follows:

Fig 3. Dendogram mosses kinship based compounds characteristic of secondary metabolites computed with NTSYS program. 1. Dicranella sp; 2. F.hygrometrica ; . B. billardierri ; 4. P. contortum

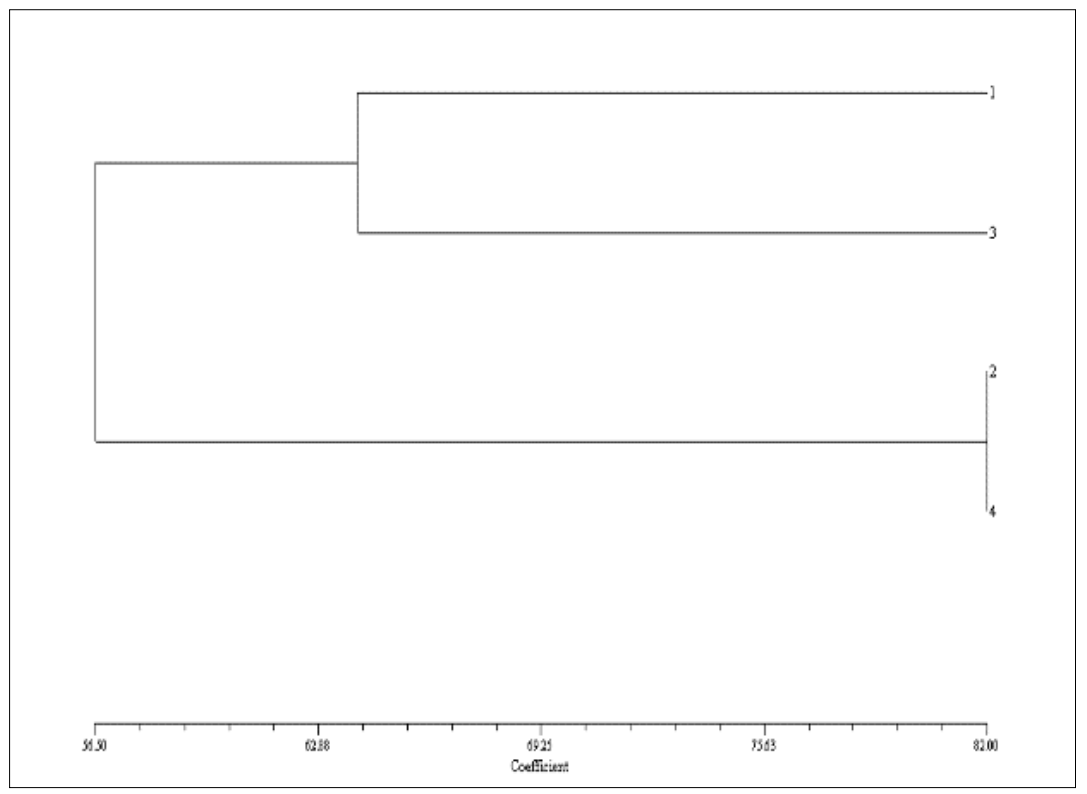

Based on the dendogram morphology and characteristics of the content of secondary metabolites, it was known that the kinship between the second mosses and third lichens $(64.71 \%)$ is closer than the kinship between the first mosses and second lichens (61.76\%) and the kinship between moss three and four $(50 \%)$. This were due between the first mosses and the second mosses have more in common, namely the leaves were elliptic and seta red and contains alkaloids, phenolics, triterenoid/steroids and terpenoids (Setiawan, 1996). Moss number two and three have similiarly which are green leaves, rosette leaf, elliptic leaves, hexagonal leaf cells, red and yellow seta and haired capsule and contains alkaloids, phenolics, triterenoid/steroids and terpenoids. Moss three and four have similiarly in leaves were green, serrated leaf edge, oblong capsule, and yellow seta and contains the alkaloid compounds, triterenoid/steroids and terpenoids (Justin, et al., 2012).

\section{Conclusions:-}

The research mosses had been conducted and found four types, namely Dicranella sp, Funaria hygrometrica Hedwig, Bryum billardierii Schwaegr and Pogonatum contortum Brid. Profile content of secondary metabolites by the compound indicates that Dicranella sp, B. Billardierii, F. and P. contortum hygrometrica contains alkaloids, phenolics, triterpenoids/steroids and terpenoids. Meanwhile, the phylogenetic based on morphology and characteristics of the content of secondary metabolites showed that the phylogenetic relationship between Funaria hygrometrica Hedwig and Bryum billardierii Schwaegr (66.67\%) is closer than between Dicranella sp and Funaria hygrometrica Hedwig (63.64\%) and the phylogenetic between Bryum billardierii Schwaegr and Pogonatum contortum Brid (51.52\%).

\section{Acknowledgements:-}

This research can be completed with the help of Lemlitbang UHAMKA and Indonesia government (DIKTI). Therefore, the researchers world like to express thanks to the Lemlitbang UHAMKA and for the cooperation of all those who have contributed in this research. 


\section{References:-}

1. Banthorpe, D.V. 1994. Terpenoids. In Mann, J., R.S. Davidson, J.B. Hobbs, D.V. Banthorpe and J.B. Harborne (eds). Natural Products: their Chemistry andBiological Significance. London: Longman.

2. B. Buchanan, W. Gruissem, R. Jones, Eds. 2012. Biochemistry \& Molecular Biology of Plants; Natural Products (Secondary Metabolites) Chapter 24. American Society of Plant Physiologists.

3. Damayanti, L. 2006. Collection of Bryophyta (mosses) in Cibodas Botanical Garden. Cibodas: Indonesian Institute of Sciences Unit, Plant Conservation Center Cibodas Botanical Garden.

4. Edward, I, J. 1991. Basics of Liquid Chromatography (Translated by Kokasih Padma Winata). Bandung : ITB Press.

5. Glime, Janice M. 2007. Bryophyte Ecology Volume 1. Physiological Ecology.

6. Gritter, R., Bobbitt, J., Schwarting, A. 1991. Introduction of Chromatography (Translated by Kosasih Padmawinata). Bandung: ITB Press.

7. Hasan, M. dan Ariyanti, N. 2004. Knows Bryophyta (Moss) in Gunung Gede Pangrango National Park. Cibodas: National Park Office Building of Gede Pangrango.

8. Hosttman, K. 1995. How Preparative Chromatography in Isolation of Natural Compounds (Translated by: Kokasih Padma Winata). Bandung : ITB Press.

9. Justin N. K., Edmond S., Ally R. M. and Xin He. 2014. Plant Secondary Metabolites: Biosynthesis, Classification, Function and Pharmacological Properties . Journal of Pharmacy and Pharmacology. Vol. 2 : 377-392.

10. Kutchan, T.M. 2001. Ecological arsenal and developmental dispatcher, the paradigm of secondary metabolism. Plant Physiology 125: 58-60.

11. Liu, Z., S.B. Carpenter, W.J. Bourgeois, Y. Yu, R.J. Constantin, M.J. Falcon. and J.C. Adams. 1998. Variations in the secondary metabolite camptochecin in relation to tissue age and season in Camptotheca acuminate. Tree Physiology 18: 265-270.

12. Muzayyinah. 2005. Vascular plant diversity. Sebelas Maret University. Surakarta : UNS Press.

13. Setyawan, A.D. 1996. Kinship Based on the Attributes of Morphology, Anatomy and Chemical Ingredients Essential Oils on Familia Members Zingiberaceae. Thesis. Yogyakarta : Biology Fakulty of UGM.

14. Sneath, P.H.A and R.R. Sokal. 1973. Numerical Taxonomy. San Fransisco : W.H. Freeman and Co.

15. Tarigan, P. 1987. Biosynthesis of Secondary Fermentation Settings, Proceedings of the National Seminar on Secondary Metabolites. Yogyakarta: UGM Press.

16. Tjirosoepomo, G. 1986. Plant Taxonomy. Jakarta: Bathara Karya Aksara.

17. Waterman, P.G. 1992. Roles for secondary metabolites in plants. In Proceedings of the $171^{\text {st }}$ Ciba Foundation Symposium on Secondary Metabolites: Their Function and Evolution, 255-75. 